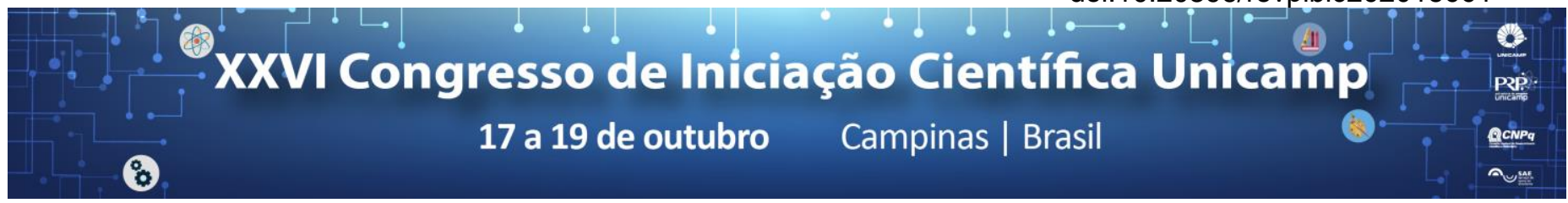

\title{
Quais os principais erros cometidos na aplicação de toxina botulínica (TXB-A) por dentistas?
}

\section{Jéssica da Silva Sousa*, Paulo Henrique Ferreira Caria.}

\section{Resumo}

A injeção de toxina botulínica do tipo A (TXB-A) é o procedimento cosmético mais comum realizado nos Estados Unidos e, juntamente com os preenchimentos intradérmicos, tornou-se a principal terapia para a prevenção e tratamento do envelhecimento facial. Esses procedimentos têm sido utilizados pelos dentistas brasileiros nos últimos 7 anos. Alguns procedimentos exigem maior perícia e conhecimento, e os resultados podem não ser alcançados. $O$ objetivo desse estudo foi identificar os erros mais comuns cometidos por cirurgiões-dentistas na aplicação da TXB-A para que seja possível desenvolver estratégias para melhorar a formação e desempenho dos futuros profissionais.

\section{Palavras-chave:}

Toxina botinulínica, músculos faciais, odontologia.

\section{Introdução}

O Conselho Federal de Odontologia (CFO) regulamentou o uso da toxina botulínica (TXB) com finalidade terapêutica pelos dentistas em 2011. O uso estético em Odontologia só foi regulamentado em 2016 e suspenso novamente no final de 2017. Desde então, não há relatos indicando as principais dúvidas apresentadas pelos dentistas após os cursos de capacitação e os erros mais frequentes cometidos por estes. Diante das diferentes possibilidades de aplicação e causas de insucesso, o objetivo desse estudo é identificar os erros mais comuns cometidos por cirurgiões-dentistas na aplicação da TXB-A.

\section{Resultados e Discussão}

Por meio de questionário digital, foram entrevistados voluntários, cirurgiões-dentistas, devidamente habilitados para o uso e manejo da TXB. Dentre as perguntas contidas no questionário, algumas avaliam como os cirurgiões dentistas se sentem em relação ao procedimento desde que concluíram o curso de capacitação no uso terapêutico da TXB em Odontologia (Tabela 1).

Tabela 1. Como os dentistas se sentem desde a conclusão do curso de especialização.

\begin{tabular}{|l|c|c|c|}
\hline & Muito & $\begin{array}{c}\text { Um } \\
\text { pouco }\end{array}$ & Nada \\
\hline $\begin{array}{l}\text { Seguro para realizar os } \\
\text { procedimentos }\end{array}$ & $18,8 \%$ & $75 \%$ & $6,3 \%$ \\
\hline $\begin{array}{l}\text { Em dúvida sobre a dose } \\
\text { a ser aplicada }\end{array}$ & $3,1 \%$ & $59,4 \%$ & $37,5 \%$ \\
\hline $\begin{array}{l}\text { Seguro sobre o local } \\
\text { correto da injeção }\end{array}$ & $34,4 \%$ & $59,4 \%$ & $6,3 \%$ \\
\hline $\begin{array}{l}\text { Em dúvida sobre a } \\
\text { anatomia do local }\end{array}$ & $3,1 \%$ & $43,8 \%$ & $53,1 \%$ \\
\hline
\end{tabular}

Quando questionados sobre a ocorrência de erros durante as aplicações da TXB grande parte dos voluntários dizem nunca ter cometido erros (Gráfico 1), porém, ainda assim, possuem muitas dúvidas em relação ao procedimento.

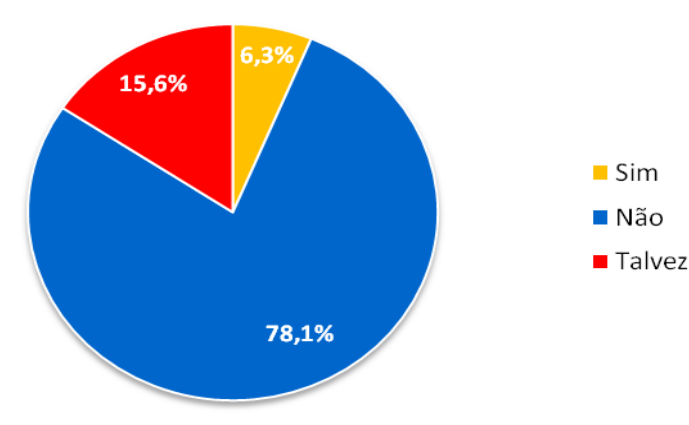

Gráfico 1. Porcentagem de cirurgiões dentistas que cometeram erros durante a aplicação de TXB.

A aplicação de TXB pode ser utilizada com fins tanto estéticos quanto terapêuticos, oferecendo excelentes resultados quando utilizada com prudência e rigor técnico. A literatura atual relata apenas as falhas cometidas por médicos na aplicação da TXB, cuja finalidade é apenas estética, sendo atribuídas à dose excessiva, erro na técnica ou na definição do local a ser aplicada.

Esse estudo permitiu que fossem indetificados os erros e as dúvidas mais comuns apresentados pelos cirurgiõesdentistas. A dose de toxina a ser aplicada e o local de aplicação são as principais dificuldades apresentadas por estes, as quais impedem que a técnica adequada seja alcançada e, consequentemente, bons resultados.

\section{Conclusões}

Com base na metodologia e nos dados obtidos, os erros mais comuns foram relacionados à dose de toxina botulínica a ser aplicada e ao local de aplicação.

\section{Agradecimentos}

Agradeço ao CNPq pela bolsa concedida para realização desse estudo.

\footnotetext{
${ }^{1}$ http://cfo.org.br/website/nota-de-esclarecimento-2/

2 Cartee TV, Monheit GD. An overview of botulinum toxins: Past, present, and future. Clin Plast Surg. 2011;38:409-26.

3 Alam M, Dover JS, Klein AW, Arndt KA. Botulinum A exotoxin for hyperfunctional facial lines: Where not to inject. Arch Dermatol. 2002;138:1180

4 Stephan S, Wang TD. Botulinum toxin: Clinical techniques, applications, and complications. Facial Plast Surg. 2011;27:529-39.
} 